Gegen Stress und für das Praxisklima

\title{
Auch für Ärzte gilt: Humor ist, wenn man trotzdem lacht
}

\author{
Sicherlich hat man als niedergelassener Arzt nicht immer etwas zu lachen. Trotzdem \\ sollten Sie sich die Fähigkeit des Humors erhalten; denn damit kann man eigenen Stress \\ besser bewältigen und auch die Motivation der Mitarbeiter steigern.
}

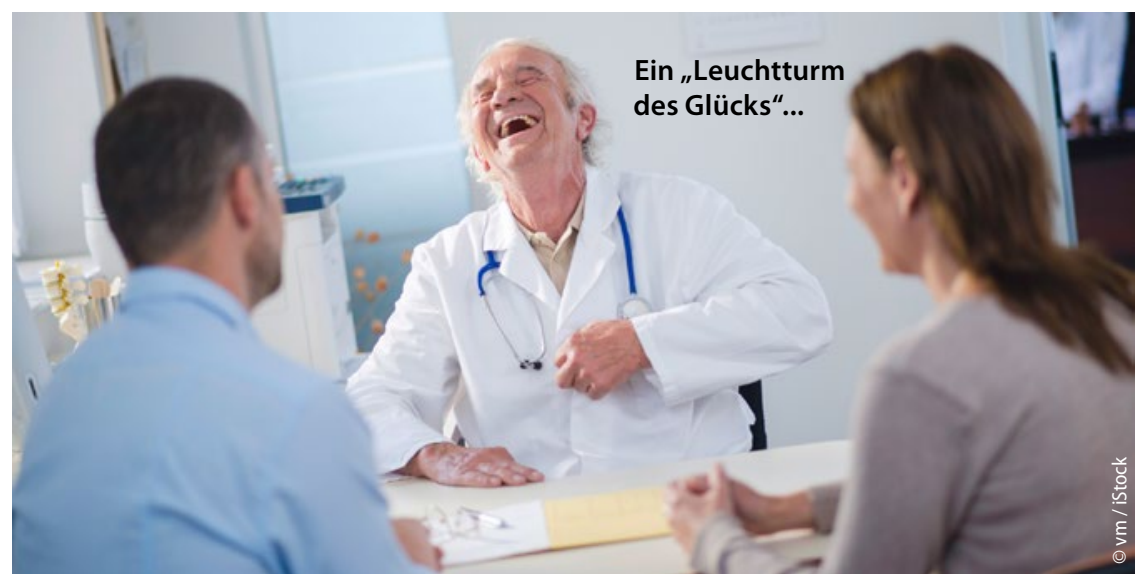

Jeder Mensch hat Humor. „Doch bei vielen Menschen, insbesondere in $\mathrm{Ge}$ sundheitsberufen, kommt er nicht zum Vorschein, ja er wird sogar unterdrückt", so M. Prehm, Lauenburg. Dabei sei Humor eine wichtige Ressource im Gesundheitsberuf, die man nutzen sollte.

die Segel anders setzen. Humorvolle Menschen wirken gerade am Arbeitsplatz wie ein Leuchtturm, der Glück, Achtsamkeit und Empathie „,ausstrahlt“. „Humorlose Menschen sterben dagegen mit vierzig und werden mit achtzig beerdigt", so Prehm. Deshalb sollten Sie gerade in stressreichen Situationen

Humor als

\section{Bewältigungsstrategie}

Humorvolle Menschen können mit Stress besser umgehen, und somit hat Humor auch einen positiven Einfluss auf die Gesundheit. Humor hilft dabei, „Humorlose sterben mit vierzig und werden mit achtzig beerdigt."

Emotionen zu regulieren, Spannungen zu reduzieren, den Blickwinkel zu ändern, von Sorgen abzulenken und zu einer optimistischen Stimmung zurückzufinden. „Nutzen Sie Humor als Airbag, lernen Sie, sich bewusst nicht zu ärgern, obwohl man im Alltag dauernd dazu Anlass hätte", so Prehm. Wenn man schon den Wind nicht ändern kann, sollte man doch vität und Flexibilität und begünstige eine positive Fehlerkultur. „Wer Humor hat, ist intelligent und selbstsicher genug, eigene Fehler zu erkennen“, so Prehm.
Empathie steigert die Motivation

Ebenso wie in der Partnerschaft entfaltet Humor auch am Arbeitsplatz eine starke Bindungskraft und verbessert die Motivation. Nach einer aktuellen Erhebung sind über $70 \%$ der Mitarbeiter nicht voll engagiert, zwei Drittel aller Arbeitnehmer möchten ihren Arbeitge-

ber wechseln und würden ein besseres Verhältnis zum Vorgesetzten einer Gehaltserhöhung vorziehen. Wie lässt sich dies verändern?

Oft sind dazu nur kleine Gesten nötig: Dankbarkeit, Zuhören, Ausreden lassen, Respekt, Achtung vor Leistung, Lob, Ehrlichkeit, Toleranz, Vertrauen, Blickkontakt, Interesse zeigen, positive Rückmeldung geben, Höflichkeit und ein freundlicher Umgangston. Wertschätzung steigert die Motivation und fördert den Teamgeist. Und dieser schützt vor Burnout und erhöht die Loyalität.

Gleiches gilt für die Empathie. Sie äußert sich in einem feinfühligen Hineinversetzen, in Toleranz, Verständnis und einem Akzeptieren von Gefühlen. Eine unabdingbare Voraussetzung für einen wertschätzenden und empathischen Umgang mit den Mitarbeitern ist Achtsamkeit „Bewahren Sie sich die Fähigkeit der Selbstreflexion, nehmen Sie feinfühlig die Signale Ihrer Umwelt auf, nehmen Sie sich Zeit für sich selbst", so Prehms Rat. Nur so könne Wertschätzung und Empathie gelingen.

Dr. Peter Stiefelhagen

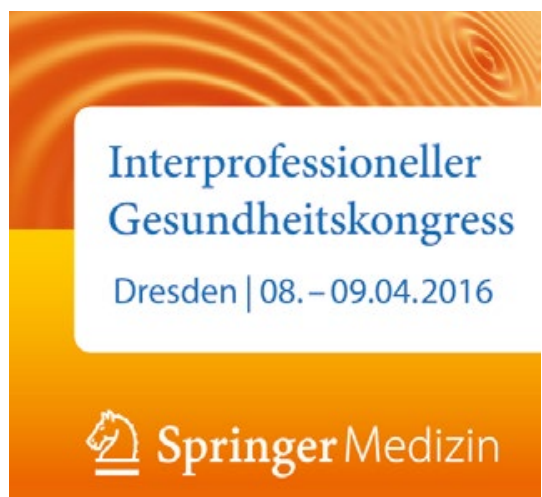

